\title{
Performance Management in Kenyan Public Schools: Implications and Challenges
}

\author{
Dorothy Owuor Jonyo, PhD \\ Education Administration and Management \\ and is currently in teacher management at TSC
}

Bonn O. Jonyo

A doctorate candidate in Business Administration, Leadership at United

States International University-Africa (academic research)

doi: 10.19044/ejes.v4no3a3 URL:http://dx.doi.org/10.19044/ejes.v4no3a3

\begin{abstract}
This paper reports findings of a recent conceptual literature review of teacher performance management systems as implemented by the Teacher Service Commission in Kenya. It was undertaken by reviewing several TSC circulars, documents used in teacher management, HR literature and the TSC Act. It reflects the perspectives of the authors and TSC management in relation to HRM good practices and theories. Its main purpose was to apprise processes from earlier procedures, to ascertain current levels of use and satisfaction, and to determine whether performance management has become a more effective strategic tool in the human resource management repertoire. The conclusions suggest, that the use of, and satisfaction with performance management systems remain challenging, although there are some indications that the increasing integration of the current perspectives of HRM appears to encourage more strategic links between individual, group, and organizational outcomes to improve TSC teacher management systems.
\end{abstract}

Keywords: Performance management, performance contract, teacher service commission.

\section{Introduction}

The review of employee performance and the management of its collective contributions to organizational effectiveness, have been perceived as a combination of informal and formal approaches which together have the potential to contribute to the motivation of individual employees and their work groups, to evaluate the efficacy of all human resource management (HRM) functions, and to provide organizations with a strategic advantage in their ongoing pursuit of competitive goals and imperatives. Recent studies, 
together with considerable anecdotal industry evidence, suggests that many organizations and their senior managers still regard performance management as a mechanistic annual ceremony which is a necessary evil, but has little bearing to their 'bottom line', with minimal recognition and understanding of the powerful tool which it can become (Price, 2011).

Performance management (PM) is a concept in the field of human resource management which is goal-oriented directed toward ensuring that organizational processes are in place to maximize the productivity of employees, teams and ultimately, the organization. It is a major phenomenon in accomplishing organizational strategy because it involves measuring and improving the value of the workforce (Gianneto, 2009). PM includes incentive goals and the corresponding values so that the relationship can be clearly understood and communicated. There is a relationship between incentives and performance. Aguinis, (2009) defines "Performance management as a continuous process of identifying, measuring and developing the performance of individuals and aligning performance with the strategic goals of the organization". Performance management often is mistaken as performance appraisal but the latter is just a part of the former.

Performance management can also be defined as a strategic and integrated approach to delivering sustained success to organizations by improving the performance of the people who work in them and by developing the capabilities of teams and individual contributions (Armstrong \& Baron, 1998). It therefore embraces both behaviour and outcomes. It is important to consider both inputs and outputs when analyzing employee performance.

Various experts have explained the concept in diverse ways. Mabey (1999) has prescribed the model of performance management system in the form of 'performance management cycle'. This cycle has 5 elements which suggest how performance management system should be implemented in an organization. These elements include: Setting of objectives; Measuring the performance; Feedback of performance results; Reward system based on performance outcomes and amendments to objectives and activities. 


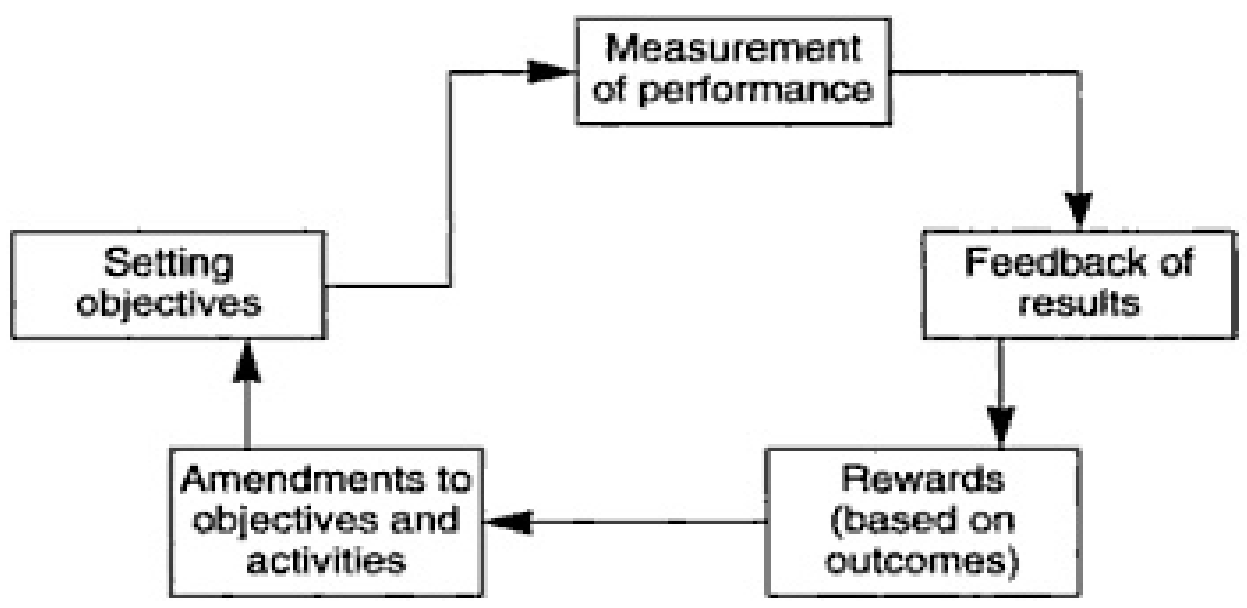

Figure 1. Performance management system Source: Mabey (1999)

Researchers have advanced two theories underlying the concept of performance management (Mabey, Salaman \& Storey,1999): The goal setting theory and Expectancy theory. Goal setting theory by John Locke suggests that the individual goals established by an employee play an important role in motivating him/her for superior performance. If these goals are not achieved, they either improve their performance or modify the goals and make them more realistic. In case the performance improves it will result in achievement of the performance management system aims (Salaman, Storey \& Billsberry, 2005).

Expectancy theory had been proposed by Victor Vroom in 1964. This theory is based on the hypothesis that individuals adjust their behavior in the organization based on anticipated satisfaction of valued goals set by them. This theory underlies the concept of performance management as it is believed that performance is influenced by the expectations concerning future events (Salaman et al, 2005).

\section{RELATED LITERATURE}

The measurement of employees' performance is the backbone of any organization's management. Organizations usually measure employee performance by assessing how much contribution the employee is making towards its growth. Performance appraisal refers to the evaluation of employees, providing them with valuable feedback and creating a positive effect on future performance (Bohlander \& Snell, 2010). Employee performance depends upon several factors such as; conducive work environment, work profile, compensation, bonus system, job satisfaction, organization policies and technology. These factors play an important role in 
determining the employee productivity and hence the overall organizational development (Gomes \& Romao, 2014).

According to TSC Corporate Communications Division 2016, in learning institutions, performance management is a systematic process of improving an institutions' performance by developing individual performance targets and those of teams. This enables heads of institutions and teachers to be involved in improving the success of their schools. The Kenya government introduced performance management in 2003 as part of its public-sector reform programme. This ensured that all public officers except for teachers were put under performance management programmes. In January 2016, Teachers Service Commission rolled out Performance Contracting for Head of Institutions (PC) and Teacher Performance Appraisal and Development (TPAD) for all teachers. The PC and TPAD are the performance management tools meant to enhance the quality of teaching and ultimately improve learning in the institutions. According to the TSC CEO Nancy Njeri Macharia in an article in the Daily Nation, Tuesday 25th April 2017, the reforms are intended to build a performance -oriented culture and instill accountability in public learning institutions.

According to TSC Annual Report 2015/2016, performance contracting and performance appraisal systems are part of the broader Public-Sector Reforms aimed at improving efficiency and effectiveness that leads to attainment of the organizational objectives. They create an understanding on how to improve performance on what should be done and how achievements will be measured. Performance management for teachers is provided for in Section 11(f) of the TSC Act which requires the commission "to monitor the conduct and performance of teachers in the teaching service and in Regulation 52 the code of Regulations of Teachers (2015). It states that "the commission shall develop an open appraisal system for teachers to strengthen supervision and to continuously monitor the performance of teachers in curriculum implementation. The TSC Annual Report 2015/2016, further institutionalized and rolled out the Performance Contracting (PC) and Teacher Performance Appraisal and Development (TPAD) system for heads of institutions and teachers to enhance effectiveness in curriculum implementation for improved learning outcomes.

Earlier a pilot programme named Teacher Performance and Integrity project (TEPIK) funded by the British Council was launched. According to the TSC Annual report 2014/2015, the Commission secured a two-year grant (2013-2015) for TEPIK. This project was jointly implemented by Teachers Service Commission and British Council. The project facilitated the revision of the Code of Regulations for Teachers and the Code of Conduct and Ethics which have been published. The grants were also used to sensitize teachers on 
the provisions of the codes distributed to all public institutions across the country.

Capacity building for staff at TSC headquarters and six counties (Kwale, Samburu, Nyeri, Uasin Gishu, Kitui and Kisumu) to support school based teacher performance was also carried out including development of appraisal instruments. Further, capacity development for TSC project staff was done where the TSC County Directors and TAC tutors were trained on the implementation of teacher appraisal system. In addition, 500 teachers were inducted in the new system. More than 75 per cent of the pilot schools recorded improvement in academic performance. Motor cycles were procured and distributed to the six pilot counties to be used for monitoring Teachers Professional Development (TAD).

\section{Tools of Performance Management}

Strategic Plan; Service Charter; Performance Contract; Work plans (Divisional \&Individual); Monitoring and Evaluation Reports; Performance Appraisal Reports and Integrated Personnel and Payroll Data (IPPD).

\section{Meaning of Performance Contracting}

Performance based contracting is a results-oriented contracting method that focuses on the outputs, quality, or outcomes that may tie at least a portion of a contractor's payment, contract extensions, or contract renewals to the achievement of specific, measurable performance standards and requirements. It is a management contract tool with a clear set of objectives to be achieved within a given period (Armstrong, 2007).

The policy decision to introduce Performance Contracts in the management of the Public Service was conveyed in the Economic Recovery Strategy for wealth and Employment Creation (ERS, 2003), since then public sector has been undertaking annual performance contracting. The national guidelines are issued by the government to provide guidance to institutions in the process of implementing Performance Contracts in the Public Service. The Teachers Service Commission has therefore derived from the National Performance Contracting Guidelines for the $12^{\text {th }}$ PC Cycle to guide heads of institutions in implementing their performance contracts.

The Performance Contract has been cascaded from the Commission Secretary and the process involves all cadres of TSC employees for complete integration. The integration includes linking the performance Contracts with the performance appraisal system and the performance incentives and sanctions. TSC, Corporate communication, (2016) states that heads of institutions negotiate on targets to be set with their respective TSC County Directors thereafter sign the performance contract. A signed Performance 
contract is an agreement between the teacher and the Teachers Service Commission which is done at the beginning of every year.

Improvement in individual or institutional performance only occurs when there is a feedback mechanism for evaluation. Feedback is having the outcomes of work communicated to the employee or institutions. For an individual employee, performance measures create a link between their own behaviour and the organization's goals. For the organization or its work unit's performance measurement is the link between decisions and organizational goals.

According to the TSC Handbook (2015), the performance contract is a commission's management tool for measuring performance against set performance targets. It is a freely negotiated performance agreement between the TSC, acting as the manager of the teaching force in the public schools, and the heads of public schools. The performance Contract specifies the mutual performance obligations, intentions and responsibilities of the parties for a given contract period.

The TSC has clearly stipulated the parties who will be involved in the performance contracting according to the Corporate Communications Division, (2016). The TSC officers at the Counties led by the TSC County Directors, Sub-County Directors and Curriculum support officers will act as the supervising agent with the main roles being; Monitor and evaluate performance; Formulation of implementation guideline

The implementing agents are head teachers in primary and post primary institutions with the main roles being; Responsible for implementation of the PC and Give progress reports on level of achievements.

\section{Objectives of Performance Contract}

The objectives of performance contract strategy in the public learning institutions include: Improving accountability for results at all levels; Reversing the decline in teacher performance with a view to enhancing learning outcomes; Institutionalizing performance oriented culture in the public learning institutions through introduction of an objective open performance appraisal system; Measuring and evaluating performance; Linking reward to measurable performance; Strengthening and clarifying the obligations required of the TSC and its employees to achieve agreed targets (TSC, 2016).

\section{Performance Contract Expected Outcomes}

The expected outcomes of the introduction of Performance Contract in the public learning institution include: Improved efficiency and professionalism in teaching service delivery for enhanced learning outcomes; Judicious management of public educational resources by ensuring that 
holders of public office (teachers and heads of schools) are held accountable for results; institutionalization of a performance-oriented culture in the public schools; Ability to measure and evaluate performance; Ability to link reward for work to measurable performance; Instilling accountability for results at all levels in the teaching service; Ensuring that culture of accountability pervades all levels of Government; Reduction or elimination of reliance on Exchequer funding by Public Agencies and Ability to strategize the management of public resources (TSC/PCPH/ANNEX 4).

\section{General Guidelines (TSC, 2016)}

1)All principals of public secondary schools and Head teachers of public primary schools will sign a performance contract with Secretary/Executive Teachers Service Commission. 2)The principals/Head teacher of Institutions and secretary (or an appointed representative) Teachers Service Commission must be present in person during the signing of the Performance Contract. 3)All targets once signed, cannot be changed midstream. 4)All primary and post primary public institutions are required to ensure availability of verifiable evidence of achievement for purposes of evaluation. 5)Primary and Post primary institutions that fail to submit performance reports based on the duly signed (Performance Contract) for evaluation, or because they declined to sign a Performance Contract shall be sanctioned. 6)The heads of institutions will monitor and report on the progress of performance targets on monthly, termly and annually using the prescribed M\&E instruments.7) The heads will submit performance target progress reports within ten (10) days following the end of a month/term/year to respective TSC County Directors. 8)The termly reports must be accompanied by an extra from the minutes of the M\&E Committee (or staff meeting) indicating that they were discussed and evidence availed and 9) The heads will receive feedback on M\&E the reports from TSC County Director with a copy to TSC HQs TM Directorate not later than 21 days after receipt of termly performance targets progress reports.

\section{Process of Performance Contract}

According to the TSC Corporate Communications Division, (2016) on performance management, the process of preparing and signing a performance contract begins at the end of third term. The Head of Institutions shall; Review achievement of targets for the ending year and carry forward to the following year any targets that have not been achieved; Set targets as per the seven preset performance criteria on and Consult the respective TSC County Director and arrange for signing of the performance contract. 


\section{Monitoring of Performance Contract Targets}

The Commission has provided monitoring and evaluation tools to be used by Heads of institutions these are the monthly, termly and annual evaluation monitoring and evaluation tools as illustrated by the table 1 .

The head of the institution is expected to come up with the monthly evaluation targets which eventually translate to the termly targets and finally annually. They will determine how much has been achieved from the signed contract and help the Sub-County Director /County Director to make an informed decision during evaluation together with tangible evidence.

\section{Meaning of Performance Appraisal}

Performance appraisal is an integral component of the overall performance management in an organization. The implementation of a credible system must be based on pre-set and established objectives. It has also to be founded on agreed targets at the start of the assessment period (TSC Image, 2017). All teachers under the TSC undergo performance appraisal based on the agreed targets that their principals and head teachers signed for their schools' performance contract.

Previously, the teaching service has been under a closed performance appraisal system where the head of institution assessed the teacher confidentially. This was shrouded in secrecy as the teacher was not involved. In the new more inclusive system, the appraiser negotiates with the appraisee on set targets and is also involved in the evaluation process (TSC Image, 2017)

Teacher performance appraisal is a method of monitoring and evaluating a teacher's performance at the school level which involves; Setting of performance targets; Periodic assessment; Feedback on evaluation; Performance based consultations; Gathering evidence to demonstrate performance; Rating of the performance; Identification of performance gaps and Planning on teacher development and support measures (TSC, 2016).

\section{Why performance appraisals for Teachers}

The Performance Appraisal tool for teachers is known as the Teacher Performance Appraisal and Development (TPAD). This is because it encompasses both evaluation of performance and mechanism to address performance gaps. Performance appraisal for teachers is expected to: Provide for a fair, objective and consistent teacher evaluation for making crucial management decisions such as assignment of teachers, deployment and promotion; Provide for fair, effective and consistent teacher evaluation; Give teachers opportunity to improve on their performance competencies and Identify teacher's performance gaps and provide support for professional development. 


\section{Benefits of Teacher Performance Appraisal}

According to the TSC Image (2017), the benefits of TPAD include; To form the basis for the reward system, including promotion and deployment to position of higher authority such as head of department, deputy headship and headship; The use of performance appraisal will enable TSC to improve performance in every learning institution in line with its vision of being an institution of excellence in the provision of efficient and effective service for quality teaching; The open appraisal system helps promote better understanding of the teacher's role by clarifying duties and responsibilities; It gives a better understanding of personal strengths and weaknesses in relation to expected performance targets; Improves communication and enhance feedback between the teacher and the supervisor thus enhancing interpersonal relationship and Help the teacher internalize the culture, norms and values of the institution.

\section{Process of Performance Appraisal}

The process of performance appraisal begins at the end of third term. Regulation 52 of the Code states that the purpose of the open appraisal system for teachers is "to strengthen supervision and continuously monitor performance of teachers in curriculum implementation at the institutional level" The following steps should be followed (TPAD MANUAL, 2016): Develop appraisal calendar at the end of third term and set departmental and individual targets and complete TPAD tool together with Appraiser; Document performance evidence throughout the term including lesson observation to be presented during appraisal; Teacher appraises and rates himself before being appraised by the appraiser; Appraisee and appraiser identify competency areas under each of the standards where the teacher has professional performance gaps and Appraisee and appraiser develop a teacher support and development plan to address performance gaps.

The appraisal report shall be shared between the teacher and the appraiser and countersigning officer or arbitrator (if or when the need arises). The appraisal reports for all teachers will then be shared with the school's Board of Management. The TSC County Director will then analyze the teachers' appraisal reports and submit the summary to the TSC headquarters.

The teachers will be appraised every school term. The termly evaluations will cumulatively constitute the annual appraisal report. Every head of institution shall submit an annual staff appraisal report to the County Director, through the Sub-County Director by every January 10th. Whenever a dispute occurs between the appraisee and the appraiser, a more senior officer other than the two will be asked to arbitrate. The Commission will take disciplinary action against a teacher who fails to complete and submit the 
appraisal report to the supervisor or refuses to discuss or sign the report with the supervisor (TPAD Manual, 2016)

\section{Rating Scale}

For the TPAD to be effective there are tools that teachers must make use of and these are; 1) Teacher Classroom/Lesson Attendance register which is marked by the class secretary /monitor and surrendered to the Deputy Head. It finally goes to the head of the Institution for filing 2) Checklist of Teacher Professional Documents. This tool contains documents which shall be used to assess if every teacher complied with the teaching performance standards. The listed records must be prepared, used, updated and maintained always, it is upon these that the teacher will be rated. The head of the institution must ensure that this check list is marked monthly by the immediate supervisor (TPAD Tool, 2016). It is signed monthly by the appraiser and confirmed at the end of each term by the Head of the Institution. 3)Checklist of the Documents to be kept by the Head of an Institution. This tool has documents which shall be used to assess whether the Head of the Institution has embraced institutional based Quality Standard Management (QSM) in maintenance of teaching standards (TPAD Tool, 2016). The Head shall ensure that records listed here are acquired, prepared, used, updated and maintained always, it is upon these that the head will be rated. This check list shall be marked every term by the immediate supervisor. It is checked monthly by the Curriculum Support Officers or Sub-County Directors at the end of the month and TSC County Director/Deputy County Director/Sub-County Director at the end of the term. 4)Lesson/Classroom Observation for Monitoring and support of TPAD implementation has been on going by the Curriculum Support Officers, Sub-County Directors, County Directors, Officers from the TSC Headquarters and Commissioners. The field officers have also been carrying out sensitization workshop for Head teachers and Deputy Head teachers. They have been using a TPAD and PC assessment tool at school level as shown hereunder;

The teacher management officers from the field and TSC headquarters came out with several outcomes using the above tools. According to the TSC CIRCULAR NO.12/2017 dated $5^{\text {th }}$ June.

\section{ACHIEVEMENTS IN IMPLEMENTATION}

The Commission noted the following remarkable achievements: 1)Compliance status: Heads of Institution and teachers have fully embraced Performance Contracting (PC) and Teacher Performance Appraisal and Development (TPAD) through signing of PCs and setting appraisal targets, and as a result the performance management tools have been entrenched into the teaching service 2)Effective time management: The implementation of 
PC and TPAD have considerably reduced teacher absenteeism from school and improved overall lesson attendance by all teachers. This entrenches a culture of client relationship with learners and other stakeholders. This has in turn impacted positively on the quality of teaching through improved syllabus coverage and curriculum delivery. While addressing Principals during their annual conference at the Wild Waters center in Mombasa in June 2015 the Chief Executive Officer of TSC Mrs. Nancy Macharia reiterated that Performance Management has gradually evolved into one of the commission's flagship projects for improving the quality of education 3)Use of professional documents: There is commendable improvement in preparation of schemes of work, lesson plans, lesson notes and learning/teaching progress Records and Record of Work are also well maintained. The teachers are now more focused and they are taking more time to prepare. They are spending more time planning for lessons and updating their teaching aids; there is more documentation on learners' progress and it is also evident that more and more teachers are planning for makeup classes. 4)Safety of Learners: There is increased sensitivity among teachers on issues pertaining to the safety of learners as demonstrated through teachers' understanding of legal and policy provisions on learners' welfare. Documentation on learners' behaviour and parental involvement in correctional programmes is in place in many schools 5) Financial management: There is improved adherence to approved budgets, improved submission of books of accounts for audit and compliance with the Public Procurement and Asset Disposal Act through tendering, evaluation, awarding and disposal procedures is becoming entrenched. This ensures prudent use of financial resources. This is expected to result in more efficiency and economic use of financial and economic use of financial resources teaching and learning programmes in all institutions 6) Supervision Heads of institution have stepped up supervision by ensuring maintenance of appraisal records, curriculum audit reports, teacher lesson attendance registers and submission of staffing returns to the Commission. Heads have become more rigorous in supervision because their targets cannot be met without teachers first delivering on their own. This has impacted positively on curriculum delivery in the various schools as they are regularly verifying professional documents for teachers and promoting teamwork 7) TPAD is giving teachers an opportunity to gauge their potentials and set targets which are achievable 8) There is promotion of co-curricular activities making the pupils/students realize their talents 9) Learners' progress records are well maintained. There is increased integration of information communication technology in teaching sourcing of appropriate teaching and learning materials from the Internet and through mobile phones and 10) There is evidence that a collaborative culture is developing in schools where teachers involve parents and guardians in the management of learner behaviour. 


\section{Challenges in Implementation of PM}

1)The greatest challenge has been understanding the tools and using them effectively. The following are examples where the tools are misunderstood:

At the beginning of every year the Performance Contract is signed between the Heads of Institutions and the Chief Executive Officer through the County Directors. The heads of the institutions should ensure the contract is implemented through targets set in the Monitoring and Evaluation forms monthly, termly and yearly. For instance, under FINANCE AND STEWARDSHIP INDICATORS, achievable targets should be set considering the Weights set and translated to $100 \%$. This should in turn be evaluated at the end of the year by the Supervisor using evidence and the Monitoring and evaluation forms. Some heads of institutions sign the contract and keep the files making evaluation difficult with no concrete evidence.

2)Some Heads of Institutions still don't understand that the Monitoring, checklist of the documents to be kept by the head teacher and Evaluation Forms are tools to help in the implementation of the performance contract while the Lesson observation tool, Lesson attendance register and the teacher's checklist are to ensure that the TPAD is effectively implemented.

3)There are cases where the Heads of Institutions evaluate themselves at the end of the year in the Performance Contract Evaluation Form instead of the supervisor. In such cases they assume that like the TPAD they should rate themselves on the PC evaluation form which is not the case.

4)The PC tool has been predetermined and is uniform for all schools in the Country yet the schools are very different in terms of categories. This makes it very difficult during evaluation.

5)During appraisal, some appraisees and appraisers fail to check on the performance indicators to ascertain that the targets were achieved.

6)Lesson Observation Indicator is a compulsory target yet some Heads of Institutions have the notion that only field officers can observe their lessons. This can be done by Heads of departments.

7)After the observation of a lesson, both the appraisee and appraiser should give their ratings on the observation areas before they agree on the final score but in most cases the appraiser gives ratings on both columns and even on the agreed score.

8)In the TPAD tool the teachers are to indicate lessons attended and not attended. This should only be done after confirming with the Deputy Head teacher who does a weekly summary of the same from the class attendance register signed by the class monitor. Some deputies are also not privy to the fact that the whole summary should be done by them. When this is correctly done then a rescheduling time table for lesson missed can be done. 
9)On the page with Appraisee/Appraiser's Remarks, they both tend to write" targets met" when they should make comments on how the appraisal process was conducted.

10)On the Teacher Support and Professional Development planning, the appraisee should be able to identify the gaps which hindered him/her from achieving the set goals while giving the recommended support/activities needed to improve on that gap. Some appraisees leave the space with performance gaps plan but fill the recommended Support space making the whole process meaningless.

11)The Arbitration space should only be signed when both the appraisee and the appraiser fail to agree on the ratings and in the presence of an Arbitrator but most teachers and their appraisers tend to fill it even where there is no disagreement.

\section{AREAS OF SENSITIZATION}

1)Work plan; All field officers are expected to prepare a work plan that should include TPAD \& PC activities. The work plan should have targets to be achieved, expected outcome and a time frame. It is expected that all schools will be visited during the term. 2)Monitoring schedule; It is important to prepare a monitoring schedule indicating the school to be visited within a specified period. Such should be maintained as one of the documents to be presented as evidence for offices' appraisal. It should have remarks showing if the schools were visited or not and reason for not visiting.

3)Monitoring tool; A monitoring tools should be used to guide the process. This will be used for collecting data, reporting and providing feedback to teachers; 4) Lesson observation and demonstration 5) Evidence based evaluation; It is expected that all evaluation will be evidence based. It is important for officers to verify the evidence used for appraisal and performance contracting. Officers are expected to visit schools to verify documents and gather evidence to justify the ratings on TPAD \& PC: 6) Professional gaps and intervention measures: Officers are expected to make a summary of the professional performance gaps identified at the zone, Sub County or county levels and propose intervention measures to address these gaps. The measures taken at each level should be documented as well as the improvements from the interventions. Officers should organize workshops and seminars at each level. Encourage head teachers to organize school based measures to address their gaps. They can form clusters and leverage on the strength of excellent teachers: 7) Feedback analysis tool

Feedback in terms of strengths and areas to improve on should be prepared and given to teacher after monitoring exercise. This should be aimed at improving the weaknesses observed: 8) Reporting: It's expected that after monitoring exercise, the officers will prepare reports and submit the same to 
the sub county, county and TSC Headquarters. The CSO should submit to the Sub County who will submit to the County Director. The county director is expected to compile and submit monthly, termly and annual reports to TSC headquarters 9) Sensitization From the various monitoring exercises, it was observed that teachers require continuous sensitization on the appraisal process and heads on the PC requirements. This calls for inset programs that will cover areas that teachers and heads have difficulties in conceptualizing. The programme for such activities will be used as evidence for the officers' appraisal.

According to the TSC /ADM/192A/VOL.IX/14 CIRCULAR NO.12/2017 of June 2017 on Evaluation of TPAD and PC the following Additional Improvement Measures were proposed; To consolidate the gains realized in the implementation of PCs and TPAD so far, the Commission has put in place measures to ensure field officers are facilitated regarding building capacity, logistics and information communication technology (ICT) infrastructure.

\section{Operational Support}

A performance contracting and appraisal Secretariat under the Quality Assurance and Standards Division has been established at the TSC Headquarters to offer operational support.

Responsibilities of County Directors County Directors will be required to: Strengthening monitoring of PC and TPAD by ensuring Heads of Institution sign performance contract based on the seven criteria and teachers are appraised on the seven teaching standards in the TPAD.

a) Visit all schools in a county and submit returns to the commission headquarters.

b) Initiate programmes for providing professional support to teachers, CSOs and SCDs in the implementation of PC and TPAD. The programmes may entail addressing performance gaps in the seven teaching standards for teachers.

c) Ensure timely submission of appraisal data for PCs and TPAD. This should be done through continuous to monitoring and evaluation of the implementation of Process.

\section{Recommendations an Effective PM}

1)Mirror the corporate culture and values 2)Have visible $\mathrm{CEO}$ and senior management support 3)Focus on the right organizational performance measures that relate to strategy, mission, and goals and cascade company goals down the structure 4)Link job descriptions to performance management system and establish accountability 5)Differentiate performance fairly and effectively 5)Train managers in performance management 6)Link 
compensation to performance management system - merit increases, actual incentives, long-term incentives, discretionary incentives 7)Communicate the total reward system 8)Require managers to actively search out, offer and acquire performance feedback on a regular basis 9)Set clear expectations for employee development 10)Track effectiveness of the performance management system. Is it able to identify trends in performance differentiation, pay differentiation, performance gaps/developmental needs? Etc. and 11) Adjust the system as required.

\section{Conclusion}

This review was conducted to ascertain whether Performance Management system as practiced by TSC has been relevant in the design, implementation, and effectiveness in Kenya, and to suggest changes that might reflect and reinforce contemporary strategic HRM theory. It was expected that the pressures of globalization, increased regional competition, industry rationalization, and a significantly more cooperative industrial relations environment, would have encouraged employers to redesign their performance management systems to reflect their competitive imperatives, and to enable closer links between individual, group, and organizational objectives and outcomes. Overall, the conclusions of the study can best be described as mixed, with evidence that substantial changes have been made with respect to the use, purposes, and nature of performance management systems, and more hopefully, that more customized and integrated systems are proposed for the future. There is need to utilize the balanced scorecard as the bridge between organizational and individual employee goals. This will ensure, the attempt to implement the strategic HRM agenda in organizations through performance management with imperatives to grow in the future. The dissatisfying factors remain to indicate the guiding principles that HRM professionals should use to further develop their performance management systems - alignment, integration, commitment, collaboration, feedback, outcomes, and user-friendliness.

Organizations can use all these approaches together effectively to evaluate the employee performance. This has positive impact on employees' motivation and they tend to improve their performance. They can identify their strengths and weaknesses and work on improving their skillsets. Since the employees are aware of the organizational goals, they can also work on improvising their skills further to achieve them. Employee performance enhances the communication between an employee and the supervisor to discuss job duties and work-related issues for a healthy work environment. With the changing trend, more recent techniques and approaches are being formulated to measure employee productivity and organizational performance which TSC should adopt to improve human capital development. Success or 
failure in performance management depends on organizational philosophies, and the attitudes and skills of those responsible for its implementation and administration, together with the acceptance, commitment and ownership of appraisers and appraisees (Hedge and Teachout, 2000).

We therefore propose a study which explores the strategic elements of systems, and the application of the balanced scorecard framework to performance management. This begins by assessing the frequency of usage of organizational vision/mission statements; articulates organizational values; critical success factors; and the balanced scorecard; and proceeds to examine the relationships between plans, missions, measures, and reviews associated with the BSC. The specific choice of the BSC will be due to its explicit and structured inclusion of performance measures with key organizational objectives and strategies.

\section{References}

Aguinis, H. (2009), $2^{\text {nd }}$ Edition. Performance Management. Dorling Kindersley India Pvt. Ltd.

Armstrong, M. (2007) Strategic Human Resource Management. A guide to Action, Kogan Page: London

Bohlander, G. \& Snell, S. (2010). Managing Human Resources, Mason: Cengage Learning

Daily Nation (2016), Teachers Appraisal System has improved Curriculum Delivery, April $25^{\text {th }}$.

Daily Nation (2017), Tough Rules on transfer of Teachers, June $25^{\text {th }}$.

Gomes, J. \& Romao, M., (2014). Advantages and limitations of performance measurement tools: The balanced scorecard. In 7th IADIS Information Systems 2014 Conference (IS 2014). Madrid: ISEG School of Economics and Management.

Giannetto, D.F. (2009), Get your Money's worth from incentives, Business Performance Management, 7

Hedge, J. \& Teachout, M. (2000). Exploring the concept of acceptability as a criterion for evaluating performance. Group and Organization Management 25 (1): 22-44.

Mabey, C., Salaman, G. \& Storey, J. (1999) $2^{\text {nd }}$ Edition. Human Resource Management: A Strategic Introduction. Blackwell Publishers Ltd.

Price, A. (2011) Human Resource Management (4th Edition). South-Western: Cengage Learning

Salaman, G., Storey, J. \& Billsberry, J., (2005) $2^{\text {nd }}$ Edition. Strategic Human Resource Management: Theory and Practice. Sage Publications Ltd.

Supervisors Guide to the Performance Management and Appraisal Process, (2005), West Virginia Division of Personnel Employee Relations Section. Teachers Image (2017), The New Regulations, Magazine. 
TSC Annual Report (2015-2016)

TSC (2016), Teaching Standards Handbook.

TSC (2016), Teachers Performance Appraisal \& Development (TPAD) manual.

TSC (2016), TPAD Tool.

TSC (2015), Code of Regulations

TSC (2017), Service Guide

TSC (2015), Handbook on Decentralized Functions.

TSC (2017), Strengthening of PC \&TPAD at Institutional Level, Circular No.14/ADM/192A/Vol.IX

TSC (2017), A Report on the Implementation of the PC/TPAD, by CSOs \& CDs KTIC/TPAD/V.1/6(62)

TSC (2016), Performance Management, Corporate Communication Division. 